\title{
Novel Classification System Of Adenoids Based On Appearance And Its Relationship With Drug Therapy
}

\author{
Huan-huan Chang ${ }^{1}$, Lu An ${ }^{1}$, Panhong Dang ${ }^{1}$, Juan Luo ${ }^{2}$, and Jie Wang ${ }^{1}$ \\ ${ }^{1}$ The Affiliated Children Hospital of Xi'an Jiao tong University \\ ${ }^{2}$ The Affiliated Children Hospital of Xi'an Jiaotong University
}

July 27, 2021

\begin{abstract}
Objective: To investigate the appropriate drug therapy based on a novel classification system for adenoids based on their appearance. Methods: We used fiberoptic nasal endoscopy to determine the degree and appearance of adenoid hypertrophy $(\mathrm{AH})$. The adenoids were divided into three types: edematous type, common type, and fibrous type. In adenoid tissues, the eosinophils were counted. Immunohistochemistry and western blot were done to determine the expression of CysLTR1, CysLTR2, CGR- $\alpha$, and CGR- $\beta$ in different types of adenoids. Results: $70.67 \%$ (106/150) AH patients with AR, and of them $68 \%(72 / 106)$ of adenoids were the edematous type. The expression of CGR- $\alpha$ and CGR- $\beta$ and eosinophil count were higher in the edematous type but not in common and fibrous types. The expression of the leukotriene receptor was stable in all types. There was a positive correlation between eosinophil count in the blood and in the adenoid tissue. Conclusion: AR was the risk factor for the development of AH. Leukotriene receptor antagonist was an important drug for the treatment of AH. The glucocorticoid was only useful in the edematous type. Therefore, for AH patients with AR, patients with edematous type adenoids and/or patients with increased eosinophils in blood routine choose nasal glucocorticoid combined with leukotriene receptor antagonist is appropriate. On the contrary, leukotriene receptor antagonists alone can be selected to treat AH.
\end{abstract}

\section{Introduction}

Adenoid tissue is a peripheral lymphoid organ located at the roof of the rhinopharynx and is part of the Waldeyer's ring. Due to its special location, especially regarding the posterior choanae and eustachian tube, it can cause various health problems in childhood. Studies have shown that adenoid hypertrophy (AH) is associated with nasal obstruction, snoring, sleep apnea, recurrent otitis media, recurrent rhinosinusitis infections, and craniofacial anomalies ${ }^{[1,2]}$. AH is commonly diagnosed using lateral radiographs and fiberoptic nasal endoscopy ${ }^{[3]}$. Most doctors choose a combination of oral Leukotriene receptor antagonists with nasal glucocorticoids in the treatment of AH. Because previous studies showed that a combination of oral Leukotriene receptor antagonists with nasal glucocorticoids showed higher therapeutic efficacy for the treatment of with less recurrence compared with single therapy using nasal glucocorticoid alone ${ }^{[4]}$. Allergic rhinitis (AR), is a non-infectious disease of the nasal mucosa, is primarily mediated by immunoglobulin E (IgE) following contact with allergens. Children with AR exhibit four main symptoms: nasal congestion, sneezing, nasal itching, and runny nose, which are usually accompanied by mouth breathing and suffocation ${ }^{[5]}$. Oral Leukotriene receptor antagonists and nasal glucocorticoids are also the first-line treatment drugs of $\mathrm{AR}^{[6]}$.

What is the immunopathology basis of AR and AH? Why are two different diseases treated with the same drugs? The appearance of AH is different. Is there any relationship between different appearance and immunopathology of AH? Here, we proposed a novel classification system of adenoids based on appearance. Additionally, we explored whether the novel classification of adenoids is helpful for drugs selection and efficacy evaluation. 


\section{Materials and methods}

\subsection{Design and participants}

We conducted a retrospective control study among patients with AR and AH in the XX Hospital. Participants enrolled from Jan 2020 to Jan 2021. AR patients were diagnosed with a positive skin prick test and the diagnosis was based on the Allergic Rhinitis and its Impact on Asthma guidelines ${ }^{[6]}$. AH was diagnosed by ear, nose, and throat specialists based on history and endoscopic physical examination ${ }^{[3]}$. The adenoid size was recorded using fiberoptic nasal endoscopy by assessing the percentage of choanal obstruction: grade I: 0 to $25 \%$; grade II: 26 to $50 \%$; grade III: 51 to $75 \%$; and grade IV: 76 to $100 \%{ }^{\text {[7] }}$. Detailed history of allergic conditions was obtained for each patient. This study was approved by the ethics committee of XX University (XJT2020- J112).

\subsection{Application and evaluation of skin prick test}

Skin prick tests were applied on the anterior surface of the forearm when they were appropriate for test such as they were not taking antihistamines. Histamine $(10 \mathrm{mg} / \mathrm{ml})$ and physiological saline were used as positive and negative references, respectively. Skin reactions were evaluated $20 \mathrm{~min}$ after the application of the skin test, and indurations of $3 \mathrm{~mm}$ was considered indicative of a positive reaction. Skin prick tests Skin prick tests including: Dermatophagoides pteronyssinus, Dermatophagoides farinea, artemisia powder,phoenix tree pollen, birch pollen, cockroach, mold, shrimp, cat and dog dander (Peking Union Medical College Hospital, Peking, China). A positive reaction was characterized as $3 \mathrm{~mm}$ or greater than that of the negative control. Skin prick test for the same allergens was performed for all patients.

\subsection{Histological assay}

The adenoid tissue specimens were fixed in $4 \%$ paraformaldehyde, embedded in paraffin, and then cut into $3 \mathrm{~mm}$ sections. The tissue sections were dried overnight at 37 and stained with hematoxylin \& eosin to count the number of eosinophils. Sections were coded and randomly analyzed by two blinded researchers using an electron microscope (Olympus, Beijing, China). After antigen resuscitation, adenoid tissue sections were incubated with $3 \% \mathrm{H}_{2} \mathrm{O}_{2}$ for $5 \mathrm{~min}$, and then with $10 \%$ normal goat serum for $10 \mathrm{~min}$. Next, the tissue specimens were incubated with anti-CysLTR1 (1:100; PA2310; Innovagen, Lund, SWEDEN), antiCGR- $\alpha$ (1:50; ab3580; Abcam, Shanghai, China), and anti-CGR- $\beta$ (1:50; ab3581; Abcam, Shanghai, China) antibodies at 37 for $1 \mathrm{~h}$. Finally, the tissue specimens were stained using diaminobenzene $(1 \mathrm{mg} / \mathrm{mL}$, Sigma).

\subsection{Western blot}

We used a protein extraction kit (Applygen Technologies, Inc.) to extract protein, followed by quantification using the Bio-Rad protein assay kit (Bio-Rad Laboratories, Inc.). Next, the protein samples (20 $\mu \mathrm{g}$ protein/lane) were separated by $12.5 \%$ SDS-PAGE and transferred to a nitrocellulose membrane (BioRad Laboratories, Inc.). The membranes were blocked with $2.5 \%$ nonfat milk at 37 for $1 \mathrm{~h}$, followed by overnight incubation with anti-CysLTR1 (rabbit; 1:1000; PA2310; Innovagen), anti-CysLTR2 (rabbit; 1: 2000; PA2320; Innovagen), and anti-CGR- $\alpha$ (mouse; 1:500; ab3580; Abcam) antibodies at 4 . Next, the membranes were exposed to horseradish peroxidase-conjugated and anti-human IgG secondary antibodies (1:200; Sigma-Aldrich; Merck KGaA) for $1 \mathrm{~h}$ at 37. The immunoreactive bands were detected using an enhanced chemiluminescence western blotting system (Thermo Fisher Scientific, Inc.).

\subsection{Statistical analyses}

Data are presented as means \pm standard deviations (SDs). Means of two continuous normally distributed variables were compared using independent samples Student's test. Chi-square and Mann Whitney U test were used to compare nonparametric values. $P<0.05$ was considered statistically significant. Analyses were performed using Graph Pad Prism 8.2.1.

\section{Results}

3.1 AR patients adenoids were mainly of edematous type. 
In outpatient clinic, we observed $150 \mathrm{AH}$ patients, 44 (29.33\%) AH patients without AR and 106 (70.67\%) with AR (Table 1). Base on the appearance of adenoids, we divided the adenoids into three types: Edematous type (Fig. 1A), common type (Fig. 1B), and fibrous type (Fig. 1C). The pathological sections showed that edematous adenoid tissue with loose structure and edema was accompanied by dilation and hyperemia of small blood vessels (Fig. 1A'); The common type was consistent with the lymphoid tissue (Fig. 1B'); The fibrous adenoid tissue exhibited dense fibrous connective tissue hyperplasia (Fig. 1C'). Among the 44 cases of AH without AR, $42(95.45 \%)$ of adenoids were found to be the common type (Fig. 1D). Among the 106 cases of AH with AR, $72(67.92 \%)$ of adenoids were found to be of the edematous type (Fig. 1E).

3.2 The expression of the leukotriene receptor was stable in all types of adenoid tissues. The expression of glucocorticoid receptor was higher in edematous type.

101 adenoid tissues were obtained from surgical patients. We found that adenoid tissues requiring surgical treatment were mostly of the common type (Fig. 2A), and children with fibrous type tissue were older than the ones with edematous type tissue (Fig. 2B). The results of immunohistochemical staining (Fig. 3A) and Western blot (Fig. 3B) showed that the leukotriene receptors were stable in all three types of adenoid tissues, and glucocorticoid receptors were highly expressed in the edematous type. Additionally, H\&E staining showed higher eosinophilic infiltration in the edematous type. We found that eosinophil count was higher in the edematous type than in the common type (Fig. 4A).

3.3 The eosinophil count of edematous type was significantly higher than that in the other two types. There was a correlation between the eosinophil count in blood and eosinophil count in the adenoid tissue.

We aimed to evaluate the effect of drug administration using endoscopic typing, blood routine, and medical history. Thus, we counted the eosinophils in different types of adenoids and found a positive correlation between the eosinophil count in blood and in the adenoid tissue (Fig. 4B). Additionally, we found no correlation between the number of eosinophils and the history of allergic diseases (Fig. 4C).

\section{Discussion}

We hope to investigate the appropriate drug therapy based on a novel classification system for adenoids based on their appearance. Thus, we divided the appearance of adenoids into three types: edematous type, common type, and fibrous type, and the pathological description was consistent with the appearance of adenoids.

In our study, we found that $70.67 \%(106 / 150)$ AH patients with AR, and of them $68 \%$ (72/106) of adenoids were the edematous type. The results showed that AR was the risk factor for the development of AH. Among the patients with AR, adenoids are mostly edematous type. Since the adenoid tissue is closer to the nasal anatomy, these areas have the same lymphatic drainage. Studies have indicated that local allergic inflammation may play an important role in childhood $\mathrm{AH}^{[8]}$. AR, asthma, and allergic dermatitis were risk factors for the development of $\mathrm{AH}{ }^{[9]}$.

Intranasal corticosteroids are known to significantly affect the production and/or activity of various proinflammatory mediators locally in the nasal mucosa, along with a decrease in vascular permeability and edema. This anti-inflammatory effect might reduce the immunological activation shown in hypertrophied adenoid tissue ${ }^{[10]}$. We found the expression of CGR- $\alpha$ and CGR- $\beta$ were higher in the edematous type but not in common and fibrous types. It is indicated that glucocorticoid was only useful in the edematous type adenoid.

Leukotrienes are the key inflammatory mediators in the respiratory system and are usually involved in the pathogenesis of childhood diseases, such as asthma. They are also systemically and locally involved in the process of inflammation in $\mathrm{AH}^{[11]}$. Studies have confirmed the overexpression of CysLTR1 ${ }^{[12]}$ and CysLTR2 ${ }^{[13]}$ in the adenoid tissue. Also, treatment with leukotriene receptor antagonist has been shown to reduce the adenoid volume ${ }^{[14]}$. In this study, we found that CysLTR1, CysLTR2 were stably expressed in 
all types of adenoid tissues. It is indicated that leukotriene receptor antagonist was the most important drug for the treatment of $\mathrm{AH}$.

Additionally, we found that eosinophil count was higher in edematous type compared with the common type, and there was a positive correlation between eosinophil count in blood and in the adenoid tissue. But there was no correlation between the history of allergic diseases and the number of eosinophils in adenoid tissue. When only lateral radiographs is available without fiberoptic nasal endoscopic results, we consult on blood routines. If a patient's blood routine shows an increased eosinophil count, eosinophils in adenoid tissue are also likely more abundant. According to our research results, we can preliminarily judge that the adenoid tissue of this patient is edematous, and the treatment of nasal glucocorticoid combined with leukotriene receptor antagonist is appropriate. On the contrary, if a patient's blood routine shows a low eosinophil count, leukotriene receptor antagonists alone can be selected to treat $\mathrm{AH}$.

\section{Conclusion}

We proposed a novel classification system of adenoids based on appearance, and divided into three types: edematous type, common type, and fibrous type. The results showed that AR was the risk factor for the development of AH. Among the children with AR, adenoids are mostly edematous type. Additionally, we found that leukotriene receptor antagonist was an important drug for the treatment of AH. The glucocorticoid was only useful in the edematous type. Therefore, for AH patients with AR, patients with edematous type adenoids and/or patients with increased eosinophils in blood routine choose nasal glucocorticoid combined with leukotriene receptor antagonist is appropriate. On the contrary, leukotriene receptor antagonists alone can be selected to treat $\mathrm{AH}$.

\section{References}

[1] Gaetano C, Stefania D, Giuseppe R, Giovanni C, Nicola M, et al. Frequency of Surgery Among Children Who Have Adenotonsillar Hypertrophy and Improve After Treatment With Nasal Beclomethasone. Pediatrics 2003, 111: 236-238.

[2] Akcay A, Kara CO, Dagdeviren E, and Zencir M. Variation in tonsil size in 4- to 17-year-old schoolchildren. Journal of Otolaryngology 2006, 35: 270-274.

[3] Saedi B, Sadeghi M, Mojtahed M, and Mahboubi H. Diagnostic efficacy of different methods in the assessment of adenoid hypertrophy. American Journal of Otolaryngology 2011, 32: 147-151.

[4] Ras AE, Hamed MH, and Abdelalim AA. Montelukast combined with intranasal mometasone furoate versus intranasal mometasone furoate; a comparative study in treatment of adenoid hypertrophy. Am J Otolaryngol 2020, 41: 102723.

[5] Cheng L, Chen J, Fu Q, He S, Li H, et al. Chinese Society of Allergy Guidelines for Diagnosis and Treatment of Allergic Rhinitis. Allergy, asthma \& immunology research 2018, 10: 300-353.

[6] Bousquet J, Hellings PW, Agache I, Amat F, Annesi-Maesano I, et al. Allergic Rhinitis and its Impact on Asthma (ARIA) Phase 4 (2018): Change management in allergic rhinitis and asthma multimorbidity using mobile technology. J Allergy Clin Immunol 2019, 143: 864-879.

[7] Cassano P, Gelardi M, Cassano M, Fiorella ML, Fiorella R. Adenoid tissue rhinopharyngeal obstruction grading based on fiberendoscopic findings: a novel approach to therapeutic management. Int J Pediatr Otorhinolaryngol 2003, 67:1303-1309.

[8] Cho KS, Kim SH, Hong SL, Lee J, Mun SJ, et al. Local Atopy in Childhood Adenotonsillar Hypertrophy. American journal of rhinology \& allergy 2018, 32: 160-166.

[9] Muhammed FE, Mahmut Dogru, Ahmet AC, and Merve LN. Adenoid hypertrophy in children with allergic disease and influential factors. International journal of pediatric otorhinolaryngology 2015, 79: 694697. 
[10] Mygind N, Nielsen LP, Hoffmann HJ, Shukla A, Blumberga G, et al. Mode of action of intranasal corticosteroids. Journal of Allergy \& Clinical Immunology 2001, 108: S16-S25.

[11] Shokouhi F, Jahromi AM, Majidi MR, and Salehi M. Montelukast in Adenoid Hypertrophy: Its Effect on Size and Symptoms. Iranian Journal of Otorhinolaryngology 2015, 27: 443-448.

[12] Dayyat E, Serpero LD, Kheirandish-Gozal L, Goldman JL, and Gozal D. Leukotriene Pathways and In Vitro Adenotonsillar Cell Proliferation in Children With Obstructive Sleep Apnea. Chest 2009, 135: 1142-1149.

[13] Paulucci BP, Pereira J, Picciarelli P, Levy D, and Di Francesco RC. Expression of cysteinyl leukotriene receptor 1 and 2 (CysLTR1 and CysLTR2) in the lymphocytes of hyperplastic tonsils: comparison between allergic and nonallergic snoring children. International Forum of Allergy \& Rhinology 2016, 6: 1151-1158.

[14] Goldbart AD, Greenberg-Dotan S, and Tal A. Montelukast for Children With Obstructive Sleep Apnea: A Double-blind, Placebo-Controlled Study. Pediatrics 2012, 130: e575-580.

Figures and Tables

Table 1. Baseline characteristics of patients. AH adenoid hypertrophy, AR allergic rhinitis, * Chi-square, ** Mann Whitney U test.

Figure 1. Novel classification system of adenoids based on appearance. (A) Edematous-type adenoids. (A') Edematous type, the tissue structure was loose, had edema, was accompanied by dilation and congestion of small vessels. (B) Common-type adenoids. (B') Common type, the whole structure was consistent with that of lymphoid tissue. (C) Fibrous-type adenoids. (C') Fibrous type, the dense fibrous connective tissue hyperplasia between lymphoid tissues. Among the 44 cases of AH without AR, 42 (95.45\%) of adenoids were found to be the common type (D). Among the 106 cases of AH with AR, 72 (67.92\%) of adenoids were found to be of the edematous type (E).

Figure 2 : The morphology and age of adenoids after surgical treatment. (A) Of the 101 cases of adenoid tissue, $30(30 \%)$ were the edematous type, $57(56.44 \%)$ were the common type, and $13(13 \%)$ were the fibrous type. (B) The age of edematous type was $59.77 \pm 4.052$, common type was $64.26 \pm 3.366$, and fibrous type was $81.77 \pm 7.122$. There was a significant difference in the age between edematous type and fibrous type $\left({ }^{*} P<0.05\right)$.

Figure 3 : Expression of leukotriene receptors and glucocorticoid receptors in the adenoid tissues of different types. (A) Immunohistochemical staining showed that the edematous type had a higher eosinophil count with larger nuclei and red cytoplasm than the common type and fibrous type. CysLTR1 was expressed in brown granules in all three types of adenoid tissues. CGR- $\alpha$ and CGR- $\beta$ were highly expressed in the edematous type, with a lower expression in the common type and fibrous type. (B) Western blot showed that CysLTR1 and CysLTR2 were expressed in all three types of adenoid tissues, and the difference in expression was not statistically significant. CGR- $\alpha$ was mainly expressed in the edematous type, which was significantly different from that in common type and fibrous type.

Figure 4 : The relationship between eosinophil count in the adenoid tissue and blood and allergic history. (A) The eosinophil count in the edematous type was higher than that in the common type $(P<0.01)$. (B) There was a positive correlation between the eosinophil count in the adenoid tissue and in the blood $\left(\mathrm{r}^{2}=\right.$ 0.1023, $P<0.01$ ). (C) There was no significant difference in the number of eosinophils in the adenoid tissue and the history of allergic disease.

\section{Hosted file}

table1.docx available at https://authorea.com/users/427792/articles/531898-novelclassification-system-of-adenoids-based-on-appearance-and-its-relationship-with-drugtherapy 


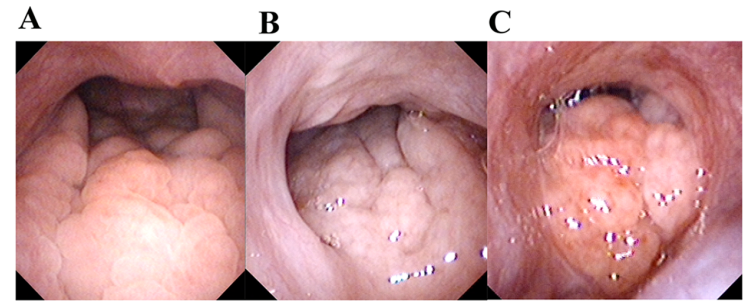

D

A'

B'

C'

Typing of AH without AR

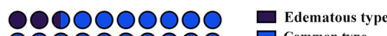

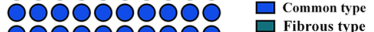
(2000 ดด

Total=44 ㅇำดoำo (10) 0 0000000000

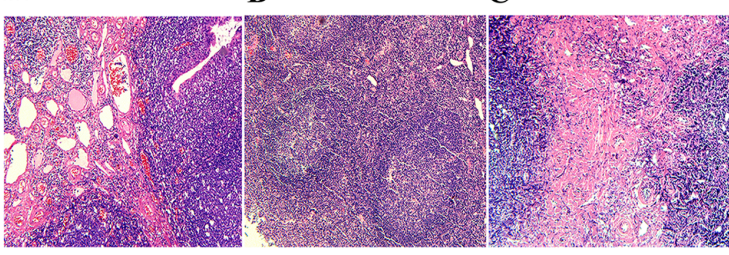

E

Typing of AH with AR

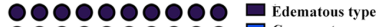

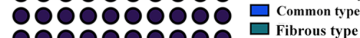

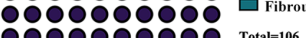

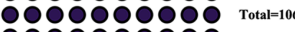

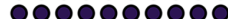

ใด

(1)

(0)

00000

(
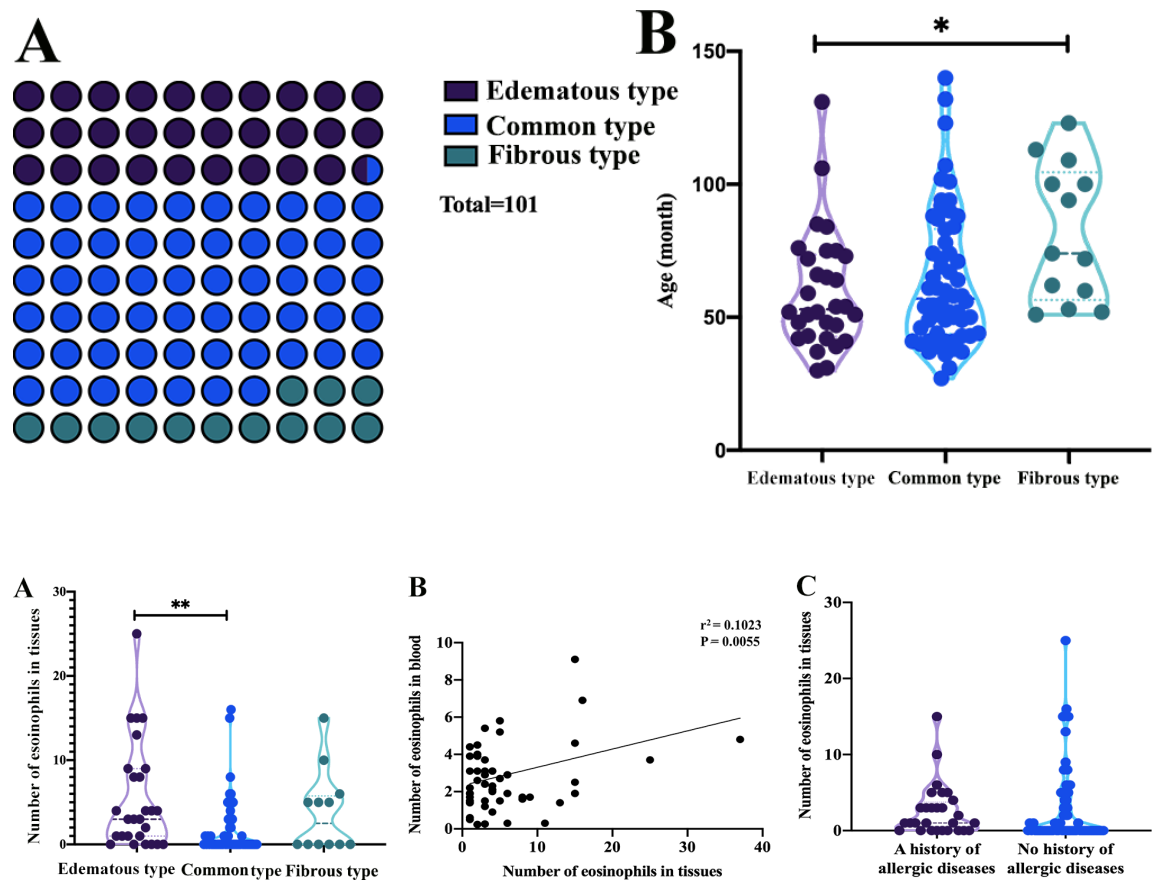


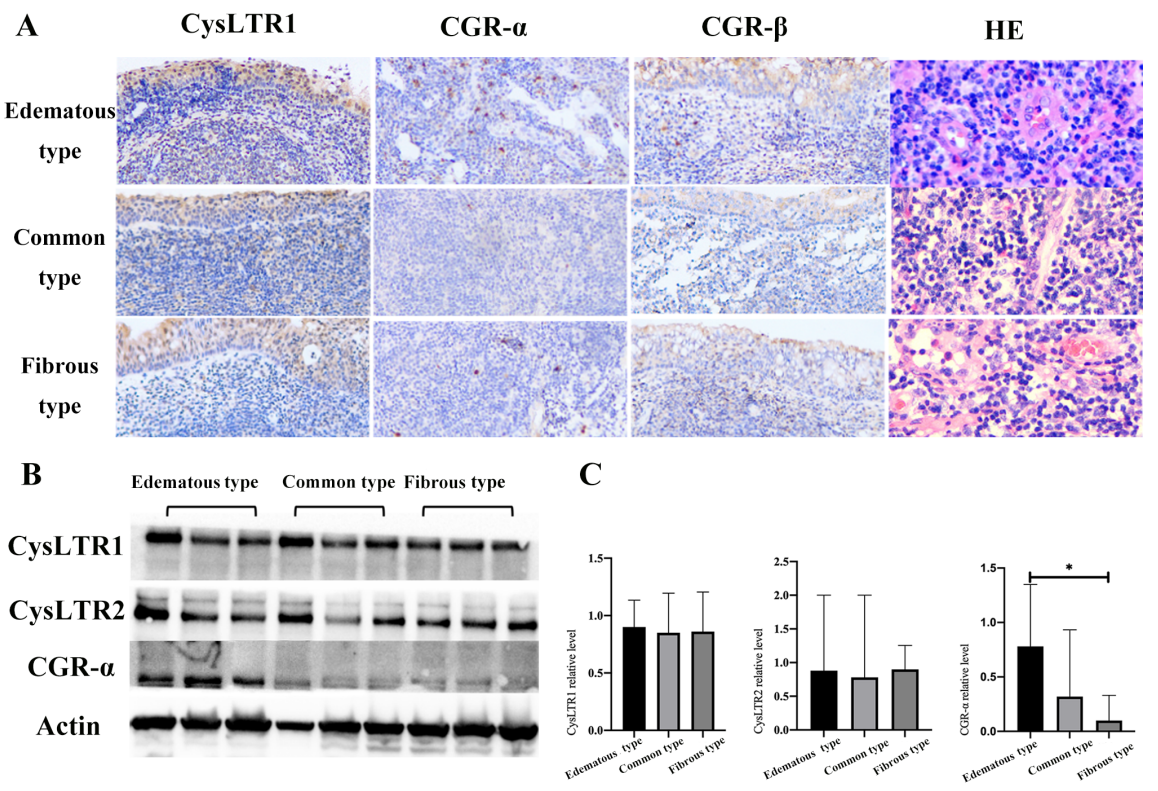

